\title{
FORMAÇÃO CONTINUADA DE PROFESSORES: O VÍDEO COMO TECNOLOGIA FACILITADORA DA REFLEXÃO
}

\author{
ANNA MARIA PESSOA DE CARVALHO \\ Faculdade de Educação da Universidade de São Paulo - Feusp \\ MARIA ELISA RESENDE GONÇALVES \\ Doutoranda pela Faculdade de Educação da Universidade de São Paulo - Feusp
}

\section{RESUMO}

O objetivo principal deste artigo é discutir o uso das gravações em vídeos, das aulas dos professores que estão em cursos de formação continuada, como uma estratégia facilitadora da reflexão desses mesmos professores sobre sua aula. A inovação que propusemos em nosso curso foi trazer as aulas dos professores para os nossos encontros. Ao fazer com que os professores discutam e reflitam sobre suas próprias ações damos a oportunidade do questionamento e da tomada de consciências de suas concepções sobre diferentes aspectos do ensino e da aprendizagem. Os dados de uma pesquisa realizada durante um curso de formação continuada são analisados.

EDUCAÇÃO CONTINUADA - FORMAÇÃO DE PROFESSORES - MEIOS AUXILIARES DE ENSINO - VÍDEO

\section{ABSTRACT}

CONTINUOUS TEACHER TRAINING: VIDEO AS A TECHNOLOGY TO FACILITATE REFLECTION. The main objective of this article is to discuss the use of video recordings of classes with professors enrolled in continuous education training courses as a strategy to facilitate these teachers reflecting on their classes. The innovation that proposed in our course was to bring the teachers' classes into our meetings. In making the teachers discuss and reflect on their own activities, we provided the opportunity for them to question and to become conscious of their own concepts about different aspects of teaching and of apprenticeship. The data from the research realized during the continued training course are analyzed. 
Um dos principais problemas que enfrentamos na formação inicial ou permanente de professores é a contradição apresentada entre seus ideais de ensino e seu desempenho em sala de aula (Carvalho, 1989a). De um lado, na universidade, discutindo teoricamente o ensino, muitos professores apresentam um discurso aberto e receptivo às novas tendências educacionais, de outro, nas escolas, em suas aulas, eles agem dogmática e repressivamente. Todas as teorias que serviram para o preparo das aulas, cujo objetivo principal deveria ser levar o seu aluno a pensar, a construir o próprio conhecimento, cai por terra quando o professor transmite o conteúdo de forma impositiva, fechada, fazendo perguntas que se limitam a: "Vocês têm dúvidas?" "Vocês estão entendendo?". Antes que eles se dêem conta, estão ensinando da mesma forma como sempre haviam feito, adaptando os novos materiais ou métodos aos padrões tradicionais.

O que temos verificado é que falar sobre, discutir ou apresentar novas propostas fundamentadas em investigações rigorosas não melhora em nada a ação do professor em sala de aula (Briscoe, 1991;Trivelato, 1993; Bell, 1998). Ser um "bom aluno" nos cursos de formação, isto é, saber identificar as variáveis que influem em um ensino, fazer planejamentos perfeitos, escolher materiais didáticos inovadores não o transformam em "bom professor". Talvez essas sejam condições necessárias, mas estão longe de ser suficientes.

Temos de inovar também em nossos cursos de formação a fim de que eles possam se apropriar das orientações didáticas propostas pelos novos currículos (Gil, Furió e Gavídia, 1998), uma vez que as pesquisas na área de educação vêm mostrando a existência de diferenças marcantes entre o objetivo perseguido pelos estruturadores de currículos e o que os professores realmente levam para a escola (Croning-Jones, 1991).

Precisamos fazer com que os professores discutam e reflitam sobre suas próprias ações em sala de aula (Schön, 1992; Nóvoa, 1992), pois há necessidade de levá-los a questionar suas concepções sobre diferentes aspectos do ensino e da aprendizagem, cuja importância nas atividades docentes pode ser tão ou mais relevante do que os conceitos espontâneos dos alunos na aprendizagem de um dado conteúdo (Hewson, Hewson, 1987). Essas concepções, como temos mostrado (Carvalho, Gil-Pérez, 1993), são frutos de experiências diárias, adquiridas sem uma reflexão e principalmente pensadas como óbvias e naturais.

Para propiciar, em nosso curso de formação, uma reflexão mais aprofundada por parte dos professores, propusemos trazer suas aulas gravadas em vídeo para os encontros. A observação em vídeo do desenrolar de cada aula e a discussão atenta sobre o desempenho do aluno, do professor, do material didático, e, 
principalmente, a interação entre eles fizeram com que o vídeo se tornasse uma verdadeira atividade de metacognição, criando oportunidades de tomada de consciência e promovendo um salto de qualidade no curso.

A fim de questionar e promover uma crítica fundamental do ensino tradicional é necessário enfocar, nas gravações em vídeo e depois nas discussões com todo o grupo de professores, aspectos especiais de uma aula como o relacionamento professor-aluno, o trabalho em grupo, o tipo de raciocínio que um dado material didático desperta, as concepções espontâneas que aparecem quando os alunos resolvem um problema, a importância de utilizar o erro para a construção do conhecimento (Carvalho et al., 1998) ou mesmo os preconceitos dos professores. Temos sempre que evidenciar que o ensino é mais do que um conjunto de elementos justapostos, e constitui uma estrutura dotada de uma certa coerência na qual cada um dos elementos vem apoiado pelos restantes (Gil et al. 1998).

Essa é uma faceta dos cursos de formação - inicial ou permanente - que se tem mostrado bastante promissora, pois discute os problemas do ensino, tomando por base situações reais do próprio ensino e tornando possíveis, pelo uso do vídeo, atividades metacognitivas entre os professores e a construção coletiva dos conceitos que envolvem o ensino e a aprendizagem, a partir da reflexão sobre a ação do professor.

\section{CONTEXTUALIZAÇÃO DA INVESTIGAÇÃO}

A pesquisa que desenvolvemos está inserida em um projeto de educação continuada para professores da Secretaria de Estado da Educação de São Paulo onde o nosso Laboratório - Laboratório de Pesquisa e Ensino de Física da Faculdade de Educação da USP - LaPEF - foi responsável pelo subprojeto: Ensino de Ciências para o Ensino Fundamental, o Conhecimento Físico.

Apresentamos nossa proposta de ensino de Ciências no contexto da discussão de algumas atividades de Conhecimento Físico para esse nível de ensino. $O$ curso centrou-se nos conceitos fundamentais, tanto os de física como os educacionais, para que pudéssemos familiarizar os professores com o raciocínio subjacente à construção dos conhecimentos pelos alunos, ajudar os alunos a expressar seu pensamento com clareza e indicar as dificuldades que se espera que os alunos encontrem ao se iniciar nesse conteúdo.

Estimulamos muito os professores a testar as atividades em suas próprias classes, na medida em que desenvolvíamos o curso. Os vídeos dessas aulas foram fontes de discussão das atividades de Conhecimento Físico e seu ensino, dando 
oportunidade para que os professores explicitassem, tomassem consciência e refletissem sobre suas concepções de ensino e aprendizagem.

Esse fato, discussão de suas próprias aulas, foi para nós fundamental, pois partimos da hipótese de que somente com uma mudança nas concepções sobre ensino e aprendizagem seria possível uma mudança metodológica (White, Gustone, 1989; White e Mitchell, 1994; Tobin, Tippins, Hook, 1994) e que essa mudança teria oportunidade se levássemos os professores a refletirem sobre sua prática e na sua prática (Schön, 1992; Nóvoa, 1992) enfocando os principais pontos do processo de ensino e aprendizagem de nossa proposta (Garcia, 1995; Azcárate, 1995).

O nosso problema foi investigar se as discussões que planejamos, a partir dos vídeos das aulas nas escolas, fizeram os professores refletirem sobre os diferentes pontos dos processos de ensino e aprendizagem de Física modificando suas concepções.

Nenhum dos dois objetivos sobre os quais havia acordado para serem alcançados era de fácil obtenção: a discussão das próprias aulas inibia os participantes e a construção de problemas que levassem os alunos a responderem o porquê dos fenômenos físicos previa uma mudança de qualidade nas perguntas a serem feitas aos alunos durante as experiências. Assim, iniciamos as discussões coletivas analisando as aulas que os professores de nosso Laboratório tinham dado na Escola de Aplicação da Faculdade de Educação e também em outras escolas da rede pública. Nessas discussões mostramos nossos erros e nossos acertos criando um clima de confiança e de respeito entre os participantes de tal modo que os professores se sentiram seguros e pouco a pouco foram trazendo os vídeos de suas aulas para que discutíssemos e então construíssemos coletivamente os pontos principais de uma prática cuja finalidade seria ensinar Ciências (o Conhecimento Físico) para alunos de sete a dez anos.

\section{METODOLOGIA DA PESQUISA E COLETA DE DADOS}

A pesquisa que empreendemos é do tipo qualitativa, uma vez que não analisamos variáveis específicas do universo educacional mas procuramos interpretar os depoimentos dos professores (Astolfi, 1993; Sheparardon, Pizzini, 1992; Loughran, 1994).

Para a coleta de dados, utilizamos três instrumentos usuais em investigação educacional: o questionário, a análise documental e a observação das gravações em vídeos. 
Foram dois os questionários utilizados: um, aplicado no encontro inicial com os professores, caracteriza-se pela superficialidade de seu alcance. São questões gerais que nos informam, de modo rápido, sobre algumas características do grupo de professores: seu tempo de experiência no magistério, seu curso de formação, a maneira como planejam suas aulas etc. O outro, respondido no nono encontro, tem a função de resgatar a experiência dos professores na aplicação das atividades de Conhecimento Físico em suas classes. Utilizamos como análise documental (Phillips, 1974; Lüdke, André, 1986) os trabalhos escritos pelos professores, em grupo ou individualmente, durante o curso. Esses documentos tiveram o objetivo de ratificar as informações obtidas pela transcrição do vídeo.

O terceiro instrumento de coleta de dados que utilizamos foi a observação de nossas aulas gravadas em vídeos. Segundo Lüdke e André:

...para que se torne um instrumento válido e fidedigno de investigação científica, a observação precisa ser antes de tudo controlada e sistemática. Isso implica a existência de um planejamento cuidadoso do trabalho e uma preparação rigorosa do observador. (1986, p. 25)

Ao optarmos por utilizar gravações em vídeo, o planejamento da gravação pareceu-nos ser o ponto-chave da observação. Planejar a gravação significa determinar com antecedência e comunicar ao operador da máquina, "o que" e "como" gravar (Carvalho, 1996).

Para a coleta de dados, utilizamos a observação dos vídeos de nossos encontros que também foram gravados integralmente. Selecionamos o que o nosso grupo de pesquisa denomina "episódios de ensino", isto é, "momentos extraídos de uma aula, em que fica evidente uma situação a ser investigada".

\section{A CONSTRUÇÃO DAS CATEGORIAS E A ANÁLISE DOS DADOS}

Como nosso objetivo era verificar as mudanças nas concepções dos professores fomos buscar evidências de que os participantes reconheciam as idéias que pretendíamos discutir. Chamamos de situações ou episódios de reconhecimento, os momentos em que os professores, pelas suas falas, comparavam suas idéias prévias com as discutidas indicando as diferenças, ou ainda explicitavam a tomada de consciência a respeito da compreensão de alguma idéia (Gonçalves, 1997).

Os episódios da categoria de reconhecimento foram retirados das gravações em vídeos do nosso curso e foram agrupados em nove subcategorias rela- 
cionadas com as principais idéias que o curso pretendia discutir. A tabela abaixo mostra as subcategorias e o correspondente em número de episódios analisados:

\begin{tabular}{|l|c|}
\hline \multicolumn{1}{|c|}{ Subcategorias } & n. de episódios \\
\hline I- A capacidade dos alunos & 16 \\
\hline II- O problema & 6 \\
\hline III- As explicações dos alunos & 10 \\
\hline IV- Os objetivos das atividades & 13 \\
\hline V- O trabalho experimental em grupos & 12 \\
\hline VI- As seqüências das etapas de ação da criança & 23 \\
\hline VII- A tomada de consciência da ação & 9 \\
\hline VIII- O papel do professor & 28 \\
\hline IX- As novidades da proposta & 6 \\
\hline
\end{tabular}

Vamos aqui apresentar alguns episódios de três categorias: I . a que mostra os professores refletindo sobre a capacidade de seus alunos ao resolverem os problemas (capacidade dos alunos); 2. a que, a partir dos trabalhos em grupo, feitos com os alunos, os professores tomam consciência da capacidade que seus alunos têm de construir conhecimento (trabalho experimental em grupo) e 3. a que mostra os professores refletindo sobre o seu próprio trabalho de ensinar (o papel do professor).

\section{CATEGORIAS}

\section{Capacidade de os alunos resolverem o problema e relatarem por escrito}

Os problemas que propomos aos alunos não têm uma solução imediata e muitos adultos os consideram difíceis. Em geral, os assuntos relacionados com a Física são evitados pelos professores das séries iniciais, que os consideram muito complicados.

Podemos somar a essas considerações outros fatos importantes. Os professores não têm o conhecimento específico dos estudos que mostram as explicações das crianças sobre os fenômenos físicos. Como, em geral, as atividades para as primeiras séries estão centradas na observação dos alunos sobre os fenômenos naturais, não é óbvio para o professor que os alunos possam elaborar uma explicação. Além disso, existe uma baixa expectativa em relação ao êxito dos alunos de níveis social e econômico pouco favorecidos. Assim, podemos justificar a importância de termos procurado, em nosso curso, dispor de todos os meios viáveis para levar os participantes a reconhecerem que os alunos são capazes de resolver os problemas propostos, de falar e escrever sobre o que fizeram durante a experiência e de dar explicações. 


\section{Contexto: quarto encontro}

Após os participantes (professores') terem visto o vídeo das crianças na atividade do pêndulo², aula dada por um dos participantes de nossa equipe na Escola de Aplicação:

Kátia: Os comentários das crianças foram melhores do que os nossos [risos]. Eu achei que eles são tão espontâneos, são tão claros. Usam palavras que nós não usamos, por exemplo, impulso. Nós falamos, mas só depois. Eles já sacaram isso, já falaram impulso, velocidade.

Rosemary: Eu não sei, mas é uma diferença tão grande da minha $3^{\text {a }}$ série, eu não sei... Os meus alunos são da favela, dentro da favela. Então, toda atividade que você vai colocar é uma tal confusão, é um tal de um agredir o outro, que você não imagina. Então a gente vê aí tudo tão direitinho, tudo tão organizado.

Geny: Aqui [Escola de Aplicação da USP, onde as atividades foram gravadas] é selecionado, não é? Tem teste.

Joseli : O hábito de dizer não, porque provém de uma classe baixa, ele também não tem condição de estar falando legal, de estar se expressando. Na verdade, isso é mentira, porque, de repente, ele pode ter um ambiente culturalmente pobre, na casa dele, mas ele observa o que acontece na rua dele, o que os outros comentam, na televisão, no jornal. De repente, ele pode estar observando estas coisas e estar...

Nesse encontro, verificamos, entremeadas nas falas dos professores, expressões de profundo descrédito quanto à capacidade dos alunos, sempre relacionadas ao nível econômico das crianças. As falas de Rosemary ("os meus alunos são da favela") e de Geny ("aqui é selecionado") são indicadoras de que a capacidade dos alunos é uma questão fundamental e delicada e aqui se revela uma série de preconceitos elaborados e enraizados ao longo da vida desses profissionais.

É preciso que as dúvidas e expressões de preconceitos aflorem para que sejam discutidas e contrapostas (Sheparardon, Pizzini 1992). $\bigcirc$ desabafo de Joseli ("porque provém de uma classe baixa, ele também não tem condição de estar falando legal, de estar se expressando. Na verdade, isso é mentira") resume a discussão que aconteceu.

\section{Contexto: sétimo encontro}

Nesse dia pudemos analisar duas aulas gravadas pelas professoras em suas próprias classes e trazidas para os encontros. Durante a discussão do vídeo que

I. Todos os nomes das professoras que antecedem os depoimentos são fictícios.

2. Ver no Apêndice, o Problema do Pêndulo. 
mostra a aula sobre o submarino ${ }^{3}$, gravada na sala da colega lara, uma das professoras participantes, numa $4^{a}$ série, destacamos as seguintes falas:

lara: Agora, quanto à experiência, teve alguns alunos ali, alunos que não gostam de escrever, que têm dificuldade tremenda de colocar... sabe aquele que levantava a mão toda hora? Ele é supertímido, a gente quase não ouve ele falar, ele levantava a mão que queria falar, era o Levi. E o Danilo, aquele capetinha que estava no fundo também, quando ele não quer assistir à aula, está dormindo ou quer ficar lá embaixo. Ele é assim bem desinteressado, fica na aula assim... e eu vi a participação dele aí nessa aula. Como ele quis participar e comentar tudo.

Cida: Eles participaram. Inclusive as crianças... eu conheço a maioria, já foram meus alunos, então eu já tenho bastante intimidade com eles. Eu sei o Levi, por exemplo, aquele loirinho, realmente para ele passar no papel... ele tem uma dificuldade muito grande de se expressar e aí ele se expressou tranqüilamente. Ele rapidamente conseguiu fazer, eu percebi que... não sei, mas pelo menos foi o primeiro a mostrar na câmera, foi o primeiro que fez. Isso até me deixou emocionada, fico muito contente de ver.

\section{Contexto: sétimo encontro}

Após os participantes terem assistido ao vídeo da colega Cida, gravado durante a atividade das sombras ${ }^{4}$, em uma classe de Ciclo Básico Inicial - CBI (antiga I a série):

Cida: Eu gostei da participação das crianças. Eu achei que todos eles inclusive o menino que conseguiu primeiro, ele não foi focalizado na hora, mas ele gritou lá atrás: "Conseguil" Foi o Anderson. Ele é do CBC [ciclo básico continuidade], mas segue o $\mathrm{CBI}$, porque não havia conseguido. Até hoje, para ele, escrever é uma dificuldade muito grande... e ele conseguiu fazer. Ele foi um dos primeiros a fazer e ele conseguiu escrever, coisa que ele não faz há muito, muito tempo. Procurou escrever com um mínimo de erros... e foi uma coisa maravilhosa. E a Vanessa, aquela escurinha que fez... a única que iniciou com o retângulo e o círculo grande inclinados, ela também é do $\mathrm{CBC}$, só que faz $\mathrm{CBI}$, e ela também tem muita dificuldade em se expressar, e tudo. E ela foi uma das primeiras a conseguir também. lara: Eu vi que as crianças, elas ficaram um bom tempo examinando o material, elas ficaram abaixando e levantando, elas ficaram testando, manipulando. Quando o garoto comentou que era difícil, eu senti: como é que podem estar fazendo, tão pequenininho!!!

3. Ver no Apêndice, O Problema do Submarino.

4. Ver no Apêndice, O Problema das Sombras Iguais. 
$\bigcirc$ curso seguiu seu caminho e a questão da capacidade do aluno, que se abrira logo nos primeiros encontros, permaneceu um ponto relevante.

Foi a partir da análise das aulas das professoras (lara e Cida) que esse reconhecimento pareceu ter-se consolidado. A fala de lara analisando determinados alunos considerados até problemáticos ("e eu vi a participação dele aí nessa aula. Como ele quis participar e comentar tudo") exprime a tomada de consciência da possibilidade de obter melhores resultados com seus próprios alunos.

A fala de Cida é ainda mais séria. Ela denuncia o fato de dois alunos que deveriam estar no CBC estarem freqüentando uma classe do CBI. Mas toma consciência também, e se alegra, de como as atividades, propondo a resolução de um problema, proporcionam aos alunos condições de se desenvolverem e como essas crianças conseguiram vencer etapas que a escola não julgava que elas seriam capazes de vencer ("até hoje, para ele, escrever é uma dificuldade muito grande... e ele conseguiu fazer... Ele foi um dos primeiros a fazer... Procurou escrever com o mínimo de erros... e foi uma coisa maravilhosa"). Isso expressa o que para nós é importante, a conscientização de que esses alunos conseguem escrever!!!

\section{Contexto: décimo encontro}

Após os participantes terem visto o vídeo da colega Cida, realizando a atividade do submarino numa I a série (CBI):

Áurea: Os professores subestimam muito a capacidade das crianças. Todos nós, não são só os professores. Mãe, todos subestimam. A gente se surpreende com aquilo que a criança devolveu para nós. $\bigcirc$ resultado foi espantoso. Tanto é que está aí o resultado, nesse vídeo. Criança que escreve corretamente, em termos de CBI. É assim uma guinada total, é fora de série. Ali, ficou bem claro que toda criança é capaz de fazer. Foi uma segurança muito grande entre as crianças, de todas fazerem e conseguirem. Todos conseguiram. Então, isto é importante, também para o professor. Serve também para o professor que rotula: "Ah! Ele não é capaz de fazer nada!" E é bem ao contrário.

Por fim, no décimo encontro, temos a fala da Áurea, ao ver os alunos do CBI da colega: "Ali, ficou bem claro que toda criança é capaz de fazer".

A seqüência das falas indica uma tomada de consciência da capacidade dos alunos, de todo o potencial que eles podem desenvolver quando o professor vence os seus próprios preconceitos e propõe atividades bem planejadas criando condições emocionais e intelectuais em suas aulas. 


\section{Capacidade de os alunos realizarem um trabalho experimental em grupo}

Procuramos encontrar maneiras de obter dos professores o reconhecimento de que o trabalho experimental em grupo, principalmente nas primeiras séries do ensino fundamental, não deve ser considerado uma fonte potencial de condutas perturbadoras da ordem da sala de aula e que as relações que se estabelecem entre os alunos no decurso da atividade têm uma influência positiva sobre o desenvolvimento das etapas de ação dos alunos até a explicação causal.

Vejamos algumas falas dos participantes a respeito do trabalho em grupo.

Contexto: segundo encontro

Após os professores terem assistido à gravação do vídeo de uma aula dada por um dos professores da equipe sobre a atividade do submarino:

lara: Quantos alunos eram na classe? Tem certos trabalhos que a gente cai sempre naquela: "Ah! Ela trabalha com poucos alunos!" E nós vimos que você trabalha com uma classe grande e o resultado foi o mesmo.

Valéria: Eles conseguiram solucionar, fazer os relatórios, em uma hora? (tom de espanto)

Nos primeiros encontros, existem mais dúvidas do que certezas sobre a possibilidade e as vantagens do trabalho em grupo com as crianças. No entanto, pudemos obter algum reconhecimento de que esse tipo de trabalho é possível. lara verificou que não é necessário que o número de alunos seja extremamente reduzido para que o trabalho experimental em grupo aconteça com êxito: "Nós vimos que você trabalha com uma classe grande e o resultado foi o mesmo."

Contexto: sétimo encontro

Após os participantes terem assistido ao vídeo da aula da colega lara realizando a atividade do submarino numa $4^{\text {a }}$ série:

Cida: E a Maíra também não brigou, nem nada. Ela não admite erro, aquela que fez a experiência e não dava certo. Porque ela não se conforma de errar nunca... e ela não brigou com ninguém. Ela ficou brava, mas...

Graça: O que eu achei assim superlegal foi da explicação. A menina não entendeu, aquela moreninha lá do fundo, não entendeu, e a explicação veio daquele... o Antônio? Aí ele explicou bem. Aí ela: "Ah! Foi isso?" Eu escutei isso no vídeo, a admiração que ela teve, do entendimento dele, da explicação dele e não do professor. Eles se entendem uns com os outros. Achei superinteressante esta parte! 
Valéria: Não teve desperdício de água, ninguém jogou água em ninguém. Eles foram bem organizados nisso. Eles gostam de bagunça, de serem os donos de tudo. Eles não. Sentaram no chão numa boa, pegaram a bacia, fizeram a atividade, não teve briga assim de "Eu faço", "Eu não faço".

Contexto: sétimo encontro

Após sessão com o vídeo da colega Cida realizando a atividade das sombras numa I ${ }^{\mathrm{a}}$ série $(\mathrm{CBI})$ :

Cristina: Acho que ela coordenou, assim, muito bem a classe. É muito difícil trabaIhar fora da sala de aula, num ambiente amplo. Acho que foi superlegal.

Contexto: décimo encontro

Após sessão com o vídeo da colega Cida realizando a atividade do submarino numa I a série $(\mathrm{CBI})$ :

Graça: Achei muito legal ter filmado aquele grupo, porque deu para perceber a linguagem de uma criança para a outra, ele explicando, a assistência que aquela menininha deu para o grupo. A colaboração, você vê um monte. Achei ótimo! Achei superinteressante este vídeo. Completou uma série de coisa. Você vê assim, coisas que a gente estava discutindo, se CBI tem condições de fazer um experimento desses. Pelo menos para mim, provou hoje, sabe.

A possibilidade de um trabalho experimental frutífero com as primeiras séries só foi reconhecida, de fato, a partir do sétimo encontro, com o início das análises das aulas das colegas. Os professores perceberam que o trabalho experimental em grupos não traz tanta confusão, como disse Valéria: "Eles foram bem organizados nisso. Eles gostam de bagunça..."

Os participantes passaram a citar nomes dos estudantes ao comentar seu envolvimento no grupo, o que fortalece ainda mais a nossa verificação de que houve o reconhecimento. Cida (sétimo encontro) mencionou a boa atuação da aluna Maíra, e Graça (sétimo encontro) estava atenta para a importância do aluno Antônio ou "daquela menininha" (décimo encontro).

A fala da Graça no décimo encontro destaca-se não só como um episódio de reconhecimento da colaboração durante o trabalho em grupo, mas também do papel que o vídeo representou nessa tomada de consciência: "Achei superlegal ter filmado aquele grupo (...). Achei superinteressante este vídeo (...). Você vê assim coisas que a gente estava discutindo". 
A importância e a possibilidade do trabalho colaborativo entre os estudantes eram idéias que queríamos discutir, pois, segundo Coll,

... dispomos na atualidade de provas suficientes que permitem afirmar sem vacilações que a interação entre os alunos não pode nem deve ser considerada um fator desprezível; ao contrário, tudo parece indicar que tem um papel de primeira ordem na consecução das metas educacionais. (1994, p. 78)

\section{Papel do professor nas atividades de Conhecimento Físico}

A nossa hipótese é a de que uma atividade de Conhecimento Físico não acontece espontaneamente. $\bigcirc$ professor tem um papel indispensável em cada uma das etapas de ação dos alunos. Se ele não propõe um problema, não há situação interessante na qual os estudantes possam agir para alargar seus conhecimentos. $\bigcirc$ professor administra os materiais, provendo os grupos de tudo aquilo de que eles necessitam. Ele pergunta, estimula e desafia, permite que todos falem e pede que escrevam.

Além disso, acreditamos que se o professor é capaz de reconhecer que a ação do aluno não é isolada, mas acontece apoiada na ação dele, deve ser capaz de utilizar os resultados obtidos pelos alunos a fim de avaliar o próprio trabalho.

Nos episódios transcritos abaixo, os professores refletem sobre suas funções.

Contexto: segundo encontro

Após os participantes terem assistido ao vídeo de uma aula dada por um membro da equipe sobre a atividade do submarino:

Cida: Esta parte é boa para a gente ver e sentir que a gente tem de ser mais calma. lara: Saber esperar, não é?

Cida: É, a sua postura é diferente da minha. Eu não sou assim uma pessoa tão calma como você. Eu achei você bastante calma no vídeo, tranqüila. Eu sou muito ansiosa!

Lucilena: Do jeito que eu sou, já dava logo as respostas para as crianças. "Ah! É assim, é assim!".

Cristina: A gente quer tanto aquela resposta... Eu já cometi muito esses erros de falar pela criança, não esperar que ela me desse a resposta.

Nesse encontro, as falas assumiram um tom de autocrítica, quando os professores comparavam a nossa maneira de conduzir a aula com a deles. Os participantes não reconheceram nossas ações específicas, mas apenas algo geral, dificil- 
mente discutível. Para eles, nossa ação resumia-se em ser calma, tranqüila. $\bigcirc$ que chamou a atenção foi o fato de permitirmos que os alunos falassem e não as perguntas que fazíamos para que eles fossem motivados a falar.

\section{Contexto: sexto encontro}

Sistematização das idéias dos participantes sobre a ação docente numa atividade de Conhecimento Físico:

Cida: [O professor] orienta. Distribui as crianças em grupo. Distribui o material. Propõe o problema. Começa a fazer as perguntas, orientando sem resolver o problema para eles.

Rosemary: No submarino você falou "Vocês já viram o submarino? Ele fica só debaixo da água ou em cima?" São perguntas relacionadas com o seu objetivo. É um estímulo.

Cida: Fazendo a pergunta, "Já viram a sombra? Com dois recortes que vocês acham que seja diferente, vocês podem fazer uma mesma sombra?", eu acho que seria o problema, porque você está propondo numa forma de pergunta que eles façam a mesma sombra com dois tipos de recorte.

lara: (...) se ele não tentou ainda, fazendo esta pergunta [propor o problema] você não está dando a resposta, mas você, de novo, está fazendo com que o aluno também pense.

Lucilena: O professor pergunta: O que você fez? Como foi resolvido? As perguntas na outra fase eram no grupo, não é isto? Agora é no geral.

Valéria: O professor pergunta no grupão "O que é a sombra?"

Cristina: Não, o que você fez para ter as sombras iguais.

Neusa: Tem que estimular realmente aquele aluno que é tímido, que não tem assim, uma participação...

Cristina: Ele pode se auto-avaliar também. Ele pode não, ele deve se auto-avaliar. Ele pode estar se questionando se agiu da maneira correta, nos momentos certos, se fez as perguntas que deveriam ter sido feitas.

Rosemary: Através da avaliação do aluno, ele vai chegar à conclusão, como ela falou, se ele agiu de forma correta ou não. Vai depender da avaliação do aluno para ele se auto-avaliar. Deixa ver se eu agi, se eu soube tratar corretamente, questionar corretamente, para chegar a uma conclusão.

A partir desse encontro, quando fizemos um trabalho em grupo com os professores pedindo para que eles sistematizassem o que tinham visto nos diversos vídeos que mostravam os trabalhos desenvolvidos em salas de aulas, os participantes passaram a delimitar as ações do professor. Há o reconhecimento de que o professor propõe um problema (Cida: "propõe o problema... perguntar para 
[ver] se entenderam o problema."; lara: ".... se ele não tentou ainda, fazendo esta pergunta [propor o problema], você não está dando a resposta, mas você, de novo, está fazendo com que o aluno também pense e que deve perguntar muito à medida que passa pelos grupos (Lucilena) e também quando a classe se reúne para a discussão (Valéria), a fim de que os alunos tenham a chance de expor suas idéias." Cida disse que ele "pergunta para outra criança do grupo se fez do mesmo jeito". Neuza resumiu dizendo que o professor não pode dar a palavra só aos mais desinibidos, mas "tem que estimular realmente aquele aluno que é tímido, que não tem, assim, uma participação".

Contexto: sétimo encontro

Após os professores terem visto o vídeo da colega lara realizando a atividade do submarino numa $4^{a}$ série:

lara: A aula foi assim, o máximo para mim. Eu acho que me empenhei bastante para preparar a aula. É uma falha que o professor tem de não preparar a aula... e a gente vai se acomodando. A gente não se empenha tanto em elaborar a aula. Então, a minha cabeça está mudando quanto a isso.

\section{Contexto : sétimo encontro}

Após os professores terem assistido ao vídeo da colega Cida realizando a atividade sobre sombras numa $I^{a}$ série $(\mathrm{CBI})$ :

Rosemary: Uma coisa que eu percebi foi que ela questionou muito os alunos: o que fizeram, por quê. Isso é o essencial, né? Ela deixou que eles falassem bastante.

\section{Contexto: oitavo encontro}

Após sessão com o programa de vídeo sobre a atividade dos carrinhos:

lara: Eu não sei se não percebi, mas foram as crianças mesmas que fizeram as regras ou foi você quem ajudou?

Rosemary: (respondendo à pergunta de lara) Eu vi, no vídeo, quando eles passaram a manusear o carrinho. Depois eles colocaram um ponto de partida e não o de chegada e você só ajudou na hora da corrida.

\section{Contexto: décimo encontro}

Após sessão com o vídeo da colega Cida realizando a atividade do submarino numa Ia série $(C B I)$ : 
Joseli: Num instante eu achei tão legal, quando o menino lá disse: "Quando eu assoprei, entrou ar", ela [Cida] perguntou: "O ar fez o que quando entrou? Por que subiu?". Ela soltava, assim, as perguntas e esperava as respostas... e eles souberam descrever muito bem.

Os participantes tinham dúvidas em relação ao tipo de intervenção que o professor deve exercer durante as aulas. lara, no oitavo encontro, questionava sobre nossa participação na elaboração das regras da competição que estava acontecendo ("... foram as crianças mesmas que fizeram as regras ou foi você quem ajudou?"). Essas perguntas indicam o reconhecimento de que os alunos trabalham orientados e de que o professor não deve ter receios ao ajudar seus alunos ou reorientar suas ações. Pelo contrário, faz parte de seu papel realizar essas intervenções nos momentos oportunos.

Rosemary, respondendo à pergunta de lara, disse que os alunos elaboraram parte das regras: "eles colocaram um ponto de partida e não o de chegada". O professor ajuda os alunos a completar suas elaborações. Isso significa perceber que ele é o guia que conhece o caminho e se compromete com ele.

Rosemary (sétimo encontro), analisando a aula da colega, comentava que "ela questionou muito os alunos. Isso é essencial, né? Ela deixou que eles falassem bastante". Também no décimo encontro, Joseli apreciava a aula da colega dizendo que ela havia elaborado as perguntas oportunas e permitido que os alunos se expressassem calmamente ("Ela soltava, assim, as perguntas e esperava as respostas...").

Por fim, os participantes reconheceram que, se a ação dos alunos depende da do professor, a avaliação dos resultados dos alunos deve também se integrar à avaliação que o professor faz de seu trabalho. A avaliação dos alunos deve servir como um instrumento que permite ao professor verificar o que não está indo bem para melhorar. Cristina: "Ele pode se auto-avaliar. Ele pode não, ele deve se autoavaliar. Ele pode estar se questionando se agiu da maneira correta, nos momentos certos, se fez as perguntas que deveriam ser feitas". Rosemary: "Vai depender da avaliação do aluno para ele se auto-avaliar".

\section{CONCLUSÕES}

Nossa hipótese inicial partia do pressuposto de que uma mudança nas concepções de ensino e aprendizagem dos professores seria obtida se levássemos esses professores a refletirem sobre sua prática e na sua prática. E essa reflexão sobre a prática e na prática seria desencadeada pelo uso do vídeo como instru- 
mento de trabalho dentro das atividades de um curso de formação continuada, pois ele permitiria trazer "a prática da sala de aula" para que refletíssemos sobre ela coletivamente em nossos encontros.

Nesses encontros, a partir dos vídeos trazidos pelas professoras de suas aulas nas escolas, elas refletiram sobre os diferentes aspectos dos processos de ensinar ciências para o ensino fundamental e discutiram as inúmeras facetas que compõem a ecologia conceitual (Strike, Posner, 1992) que cerca os conceitos de ensino e de aprendizagem.

A possibilidade de gravar em vídeo o comportamento docente, o que enseja o pensar coletivo sobre a aula dada em suas várias facetas, contribui de maneira decisiva para a dinâmica e a qualidade dos encontros entre professores e a equipe da universidade com o objetivo de proporcionar uma educação continuada, tanto dos professores quanto da equipe. As imagens do vídeo causam impacto e falam por si mesmas. Favorecem a relação teoria-prática, na medida em que o comportamento docente e de seus alunos mostrado no vídeo precisa ser analisado e explicado.

Pela análise de nossos dados é possível dizer que, ao refletirem sobre o seu ensino e sobre a aprendizagem de seus alunos, os professores tomaram consciência da interligação desses conceitos e assim os reelaboraram, ou seja, construíram um novo conhecimento sobre o ensino, a aprendizagem e a relação entre ambos, que não se restringe ao ensino e à aprendizagem de Ciências, ao contrário, ultrapassa-os.

\section{REFERÊNCIAS BIBLIOGRÁFICAS}

AlvarengA, B., MÁXIMO, A. Curso de física. São Paulo: Harbra, 1993, p. 906.

ASTOLFI, J. P. Trois paradigmes pour les recherches en didactique. Revue Française de Pédagogie, n. 103, p. 5-18, 1993.

AZCÁRATE, P. Las concepciones de los professores y la formación del professorado. In: BLANCO, L. J., MELLADO, V. (coords.). La Formación del Profesorado de Ciencias y Matemáticas en España y Portugal. España: Badajóz, 1995, p. 39-48.

BELL, B. Teacher development in science education. In: FRASER, B. J., TOBIN, K.G. (eds.) International handbook of science education. Dordrecht: Klubr, 1998.

BRISCOE, C. The Dynamic interactions among beliefs, role methaphores and teaching practices: a case study of teacher change. Science Education, v. 75, n. 2, p. 185-99, |99|. 
CARVALHO, A.M.P. Física: proposta para um ensino construtivista. São Paulo: Editora Pedagógica Universitária, 1989.

. A Formação de professores: o discurso crítico liberal em oposição ao agir dogmático repressivo. Ciência e Cultura, São Paulo, v. 4I, n. 5, p. 432-4, 1989 a.

- O Uso do vídeo na tomada de dados: pesquisando o desenvolvimento do ensino em sala de aula. Pro-Posições, Unicamp, v. 7, n. I, p. 5-13, mar. 1996.

CARVALHO, A.M.P., GIL-PÉREZ, D. A Formação de professores de ciências. São Paulo: Cortez, 1993.

CARVALHO, A.M.P. et al. Ciências no ensino fundamental: o conhecimento físico. São Paulo: Scipione, 1998.

COLL, C. Aprendizagem escolar e construção do conhecimento. Porto Alegre: Artes Médicas, 1994.

CRONING-JONES, L.L. Science teacher beliefs and their influence on curriculum implementation: two case study. Journal of Research in Science Teaching, v. 28, n. 3, p. 235-50, 1991.

DUGAS, R. Histoire de la mecanique. Neuchatel: Editions du griffon, 1950.

GARCIA, M.C. Formación del profesorado para el cambio educativo. Barcelona: EUB, 1995.

GIL, D.; FURIÓ, C., GAVÍDIA V. El Profesorado y la reforma educativa en España, Investigación en la escuela, n. 36, p. 49-64, 1998.

GONÇALVES, M.E.R. Atividades de conhecimento físico na formação de professores das séries iniciais. São Paulo, 1997. Tese (dout.) Feusp.

GONÇALVES, M.E.R., CARVALHO, A.M.P. As Atividades de conhecimento físico: um exemplo relativo à sombra. Cadernos Catarinenses de Ensino de Física, v. 12, n. I, p. 7-16, 1995.

Uma Atividade sobre impulso e quantidade de movimento para a escola primária. In: SIMPÓSIO DE PESQUISAS DA FACULDADE DE EDUCAÇÃO DA USP, I Anais... São Paulo, 1994a, p. 40 I-13. (Série Estudos e Documentos)

Um Exemplo de atividade de conhecimento nas primeiras séries do primeiro grau: o problema do submarino. Cadernos de Pesquisa, n. 90, p. 72-80, ago. 1994.

HEWSON, P. W., HEWSON, M.G. Science teachers conceptions of teaching: implications for teachers education. International Journal of Science Teaching, v. 9, n. 4, p. 42540, 1987. 
INHELDER, B., PIAGET, J. Da Lógica da criança à lógica do adolescente. São Paulo: Pioneira, 1976.

LOUGHRAN, J. Bridging the gap: an analysis of the needs of second-year science teachers. Science Teacher Education, v. 78, n. 4, p. 365-86, 1994.

LÜDKE, M., ANDRÉ, M.E.D.A. Pesquisas em educação: abordagens qualitativas. São Paulo: EPU, 1986.

NÓVOA, A. (coord.) Os Professores e sua formação. Lisboa: Dom Quixote, 1992.

PHILLIPS, B. S. Pesquisa social. Rio de Janeiro: Agir, 1974.

PIAGET, J. Les Notions de mouvement et de vitesse chez l'enfant. Paris: PUF, 1946.

SCHÖN, A. D. Formar professores como profissionais reflexivos. In: NÓVOA, A. (coord.) Os Professores e sua formação. Lisboa: Dom Quixote, 1992.

SHEPARARDON, D.P., PIZZINI, E. L. Gender bias in female elementary teachers' perceptions of the scientific ability of students. Science Education, v. 76, n. 2, p. 147-53, 1992.

STRIKE, K., POSNER, G. A Revisionist theory of conceptual change. In: DUSCHL, R.S., HAMILTON, R. (eds.) Philosophy of science: cognitive psichology and educational theory and practice. Albany Suny Press, 1992.

TOBIN, K. G., TIPPINS, D.J., HOOK, K. Referents for changing a science curriculum: a case study of one teacher's change in beliefs. Science \& Education, v. 3, n. 3, p. $245-64,1994$.

TRIVELATO, S.L.F. Ciência, tecnologia e sociedade: mudanças curriculares e formação de professores. São Paulo, 1993. Tese (dout.) Feusp.

WHITE, R. T., GUSTONE, R. F. Metalearning and conceptual change. International Journal Science Education, v. II, p. 577-87, 1989.

WHITE, R. T., MITCHELL, I. J. Metacognition and the quality of learning. Science Education, v. 23, p. $21-37,1994$. 


\section{APÊNDICE}

\section{O PROBLEMA DO PÊNDULO}

Uma das grandes preocupações dos filósofos no século XVII era o fato de que todos os objetos que se encontram em movimento acabam sempre, depois de um certo tempo, perdendo velocidade e parando. Essa observação parecia indicar que o "movimento total" do Universo estava diminuindo e, conseqüentemente, "o Universo estaria morrendo", fato inaceitável, pois, sendo o Universo obra divina, ele deveria ser eterno. Por esse motivo, vários cientistas e filósofos da época acreditavam na possibilidade de existência de alguma grandeza, relacionada com o movimento, que permaneceria inalterada enquanto os corpos interagiam, mesmo que alguns deles acabassem por parar (Alvarenga, Máximo, 1993).

Desenvolvem-se, então, idéias acerca da conservação da quantidade de movimento, as quais, juntamente com a conservação da energia e da carga elétrica, constituem um dos princípios fundamentais da Física.

Para discutir o significado dessa grandeza chamada "quantidade de movimento", poderíamos começar com uma pergunta: Como provocar movimento num corpo? Uma possível resposta seria: através da interação deste com outro corpo em movimento.

Mas de que depende o poder de modificação do estado de movimento de um corpo quando de sua interação com outro corpo? Galileu, no século XVII, daria uma resposta a essa questão: "[...] Dois pesos absolutamente iguais, movidos com velocidades iguais, têm o mesmo poder ou o mesmo 'momento' em todas as suas operações" (Dugas, 1950).

Descartes, contemporâneo de Galileu, chamaria atenção para a possibilidade de existência do mesmo tanto de 'movimento' em partes diferentes de matéria. Ele dizia que, ao considerarmos uma parte da matéria que se move com uma velocidade duas vezes maior que outra parte, se essa outra parte for duas vezes maior que a primeira, então existe tanto "movimento" na maior quanto na menor. Podemos ver a compensação estabelecida entre velocidades e quantidades diferentes de matéria, contanto que diferentes numa proporção tal que seu produto seja o mesmo.

Percebemos que o que Galileu denomina "momento" e Descartes, "movimento" é uma grandeza ligada simultaneamente à massa e à velocidade de um corpo; essa grandeza é também chamada "quantidade de movimento". E é essa 
"quantidade de movimento" dos corpos que pode ser modificada quando eles interagem. Isto se dá, por exemplo, na colisão entre duas bolinhas, quando uma delas, inicialmente parada, passa a se movimentar após o choque.

Pensando numa colisão desse tipo, poderíamos perguntar: Que fatores estão envolvidos no movimento subseqüente das bolinhas? Em outras palavras: o que determina a quantidade de movimento que será perdida pela primeira bolinha e adquirida pela outra?

A quantidade de movimento adquirida pela bolinha que estava inicialmente parada depende de sua massa, e também da massa e da velocidade da bolinha que a atingiu. Por depender da massa e da velocidade da bolinha incidente, bolinhas de massas diferentes, contanto que com determinadas velocidades, podem produzir na bolinha parada o mesmo efeito - para tanto, é preciso que se tenha a compensação entre velocidade e massa apontada por Descartes. Quando isso acontece, os físicos (e parte das crianças!) dizem que as bolinhas que estavam em movimento aplicaram o mesmo impulso à bolinha parada; em outras palavras, a interação das diferentes bolinhas em movimento com a bolinha parada provocou, nessa última, a mesma variação da quantidade de movimento.

Sabemos que a idéia de quantidade de movimento é fundamental para a Física. E que seu estudo na escola inicia-se no ensino médio, em que os alunos já articulam as estruturas do pensamento formal. Entretanto, as raízes das noções de quantidade de movimento e impulso (variação da quantidade de movimento) já estão presentes nas crianças pequenas (Carvalho, 1989a; Piaget, 1946). A razão disso é que essas noções estão muito ligadas às atividades de toda criança que, desde muito cedo, produz e observa movimento de objetos (Gonçalves, CarvaIho, 1994a).

Foi então, a partir da importância histórica da noção de quantidade de movimento e de sua variação, além da possibilidade de trabalhá-los com as crianças, que elaboramos as seguintes atividades.

\section{O Material}

Devem ser distribuídos, para cada grupo: um trilho, duas bolinhas de mesmo tamanho e massas diferentes, pêndulo, bacia ou caixa de papelão.

A bacia deve ser usada para aparar as bolinhas, impedindo que elas rolem pelo chão, causando confusão ou eventuais acidentes no caso de as crianças pisarem nas bolinhas e escorregarem. $O$ pêndulo deve estar montado de tal forma que a bolinha, ao fim de seu movimento pelo trilho, choque-se com ele, como na ilustração a seguir. 


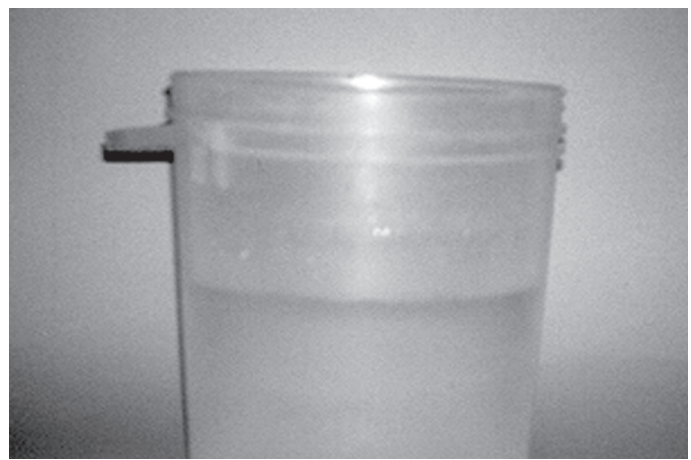

O Problema

Colocar uma bolinha de cada vez no trilho e encontrar uma maneira de fazer com que cada bolinha levante o pêndulo o mesmo tanto.

\section{O PROBLEMA DO SUBMARINO}

Segundo Inhelder e Piaget (1 976), na classificação de objetos em flutuantes e não flutuantes, as crianças não buscam, num primeiro momento, explicação única e não contraditória para essa sua seleção. A tendência subseqüente é caracterizada por um esforço da criança em afastar a contradição de que alguns objetos grandes podem flutuar e alguns objetos pequenos podem afundar, enquanto em sua concepção, objetos leves flutuam e objetos pesados afundam. Somente quando a noção de conservação do volume estiver bem constituída para a criança, ela poderá explicar de maneira não contraditória as suas classificações.

Na nossa atividade, tendo-se em vista a complexidade das relações envolvidas no conceito de flutuação, uma das variáveis relevantes - o volume - é controlada de antemão: o volume do submarino utilizado na experiência é fixo. Com isso, não propomos uma atividade para os alunos classificarem objetos, mas criamos uma situação na qual a explicação causal para a flutuação torna-se possível de ser dada pelas crianças.

É interessante observar que a atividade do submarino é muito encontrada nos livros de Ciências para o ensino fundamental. Entretanto, em geral, a atividade 
que o professor sugere aos alunos restringe-se à construção do submarino. No nosso caso o submarino é apenas um instrumento pelo qual o aluno investiga o fenômeno físico da flutuação.

\section{Material}

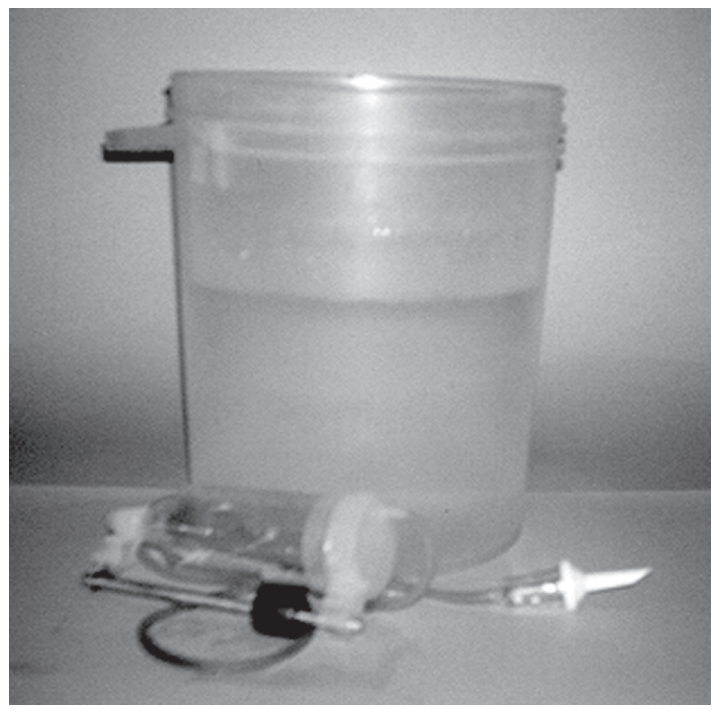

O Problema

Devem ser distribuídos, para cada grupo de quatro a cinco crianças: um submarino, uma bacia com água e, por medida de higiene, um bocal para cada aluno. Além disso, como em todas as atividades nas quais os alunos manipulam água, são necessários panos ou papel-toalha para secar o local. O problema é fazer o submarino subir e descer.

\section{O PROBLEMA DAS SOMBRAS IGUAIS}

Tendo em vista a complexidade que o conceito científico de sombra representa para as crianças e a recorrência da idéia de sombra como substância pertencente ao objeto, elaboramos esta atividade. Nela, as crianças podem testar algumas hipóteses associadas à idéia substancialista.

Em primeiro lugar, a hipótese de que a sombra depende da cor do objeto levou-nos a apresentar aos alunos objetos de cores diferentes. No experimento, os alunos constatam que essa característica do objeto não influencia, em nenhum aspecto, a sombra formada por ele. 
Além disso, as crianças tomam consciência de que a sombra não depende unicamente de características do objeto, como sua forma ou dimensão, não se constitui no "reflexo" ou "retrato" do objeto. Para tanto, apresentamos aos estudantes figuras de formas (círculos, quadrados e retângulos) e dimensões diferentes. Para obterem sombras iguais (este é o problema proposto) com as diferentes dimensões e formas dos objetos dos quais dispõem, as crianças têm que se valer de duas variáveis que colocam em evidência a importância da fonte de luz na produção das sombras: a distância entre a fonte e o objeto e a orientação do objeto em relação à fonte. A variação na orientação do objeto em relação à fonte de luz produz sombras diferentes dos objetos.

\section{O Material}
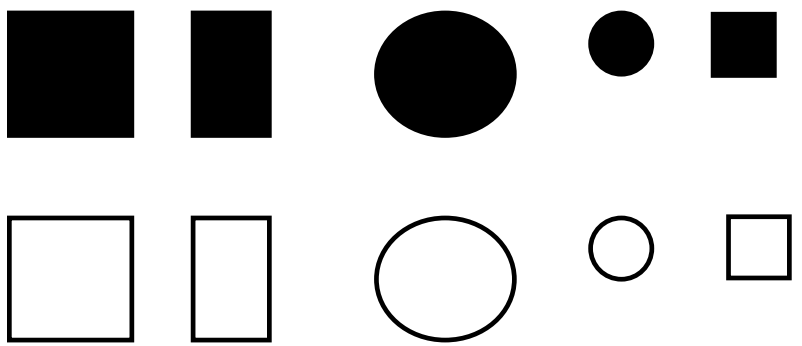

Devem ser distribuídos, para cada grupo, que deve ser pequeno (quatro a cinco alunos): um conjunto de círculos, quadrados e retângulos de dimensões e cores diferentes. As sombras dessas figuras serão projetadas numa superfície clara, que pode ser uma cartolina branca. Para isso, cada grupo deve dispor de uma luminária com a lâmpada voltada para o chão.

A atividade também pode ser realizada ao ar livre. Nesse caso, o Sol substitui a luminária como fonte de luz.

Ainda outra maneira é substituir a luminária por uma vela. Nesse caso, a cartolina branca não é necessária, pois os alunos projetarão as sombras na parede (é preciso que a parede seja clara). Trata-se de uma alternativa fácil e barata que, no entanto, pode ser perigosa. É preciso muita atenção do professor, que deve tomar certos cuidados indispensáveis para que as crianças não se queimem; por exemplo: fixar as velas em suportes que as crianças não devem movimentar, afastar papéis, prender cabelos etc. 
O Problema

O professor distribui o material para cada grupo e propõe o problema: "Vocês vão pegar duas figuras que achem que são diferentes. E vão tentar fazer sombras iguais com elas". 